\title{
APRENDIZAGEM-SERVIÇO E FÓRUNS COMUNITÁRIOS: ARTICULAÇÕES PARA A CONSTRUÇÃO DA CIDADANIA NA EDUCAÇÃO AMBIENTAL
}

\author{
Marco Antonio Morgado da Silva ${ }^{1}$ \\ Ulisses Ferreira Araújo ${ }^{2}$
}

\begin{abstract}
RESUMO
O conceito de cidadania ocupa posição central no escopo das diferentes perspectivas que configuram o campo da Educação Ambiental. Não obstante, os significados atribuídos ao conceito, bem como a proposição de estratégias metodológicas dirigidas a sua construção, nem sempre têm sido devidamente explorados. Este artigo explora as implicações teórico-metodológicas da cidadania com a Educação Ambiental, conferindo destaque ao potencial que a articulação entre a metodologia da Aprendizagem-Serviço e a ferramenta dos Fóruns Comunitários pode aportar para a construção da cidadania no âmbito da educação formal.
\end{abstract}

Palavras-chave: Educação Ambiental; Cidadania; Aprendizagem-Serviço; Fóruns Comunitários.

\section{COMMUNITY LEARNING AND COMMUNITY FORUMS: ARTICULATIONS FOR THE CONSTRUCTION OF CITIZENSHIP IN ENVIRONMENTAL EDUCATION}

\begin{abstract}
The concept of citizenship occupies a central position in the scope of the different perspectives that shape the field of Environmental Education. Nevertheless, their meanings, as well as the methodological strategies capable of promoting its construction, have not been properly explored. The main goal of this article is to explore the theoretical and methodological implications of citizenship with Environmental Education, giving special attention to the potential that the Service Learning methodology and Community Forums have for the construction of citizenship in the school.
\end{abstract}

Key-words: Environmental Education; Citizenship; Service Learning; Community Forums.

\footnotetext{
${ }^{1}$ Mestre em Educação pela Faculdade de Educação da Universidade de São Paulo. E-mail: marcomorgado.s@gmail.com

${ }_{2}^{2}$ Professor Titular da Escola de Artes, Ciências e Humanidades da Universidade de São Paulo (EACH/USP leste). E-mail: uliarau@usp.br
} 


\section{INTRODUÇÃO}

Nas últimas décadas, o conceito de bem comum tem atravessado os diversos debates que configuram o campo ambiental, problematizando o caráter público da questão ambiental e trazendo à baila reivindicações relativas à democratização do acesso aos bens e serviços ambientais e à responsabilidade que todos devem assumir pelos destinos do mundo comum. Em um contexto em que o meio ambiente tem sido apropriado de modo desigual pelos diferentes atores sociais (ASCELRAD; HERCULANO; PÁDUA, 2004), fazendo prevalecer os interesses privados em detrimento do interesse público, e acarretando em exclusão social e degradação ecológica, a Educação Ambiental (EA) figura como uma prática social de fundamental importância para a afirmação de valores como a justiça social, a solidariedade, a sustentabilidade ecológica e a democracia.

Consoante essa perspectiva, partimos da concepção de que a cidadania deve constituir o horizonte formativo e diretriz das práticas de EA, de modo a pautar a questão ambiental nos marcos de uma problemática ético-política e contribuir com a formação de cidadãos sensíveis e críticos aos problemas socioambientais, capazes de problematizar, compreender e implicar-se ativamente com as demandas que concernem ao mundo comum. Filiamo-nos, nesse sentido, à vertente da EA denominada Crítica, Emancipatória, Popular ou Transformadora, que insere a EA em um projeto de transformação social, cujo propósito político-pedagógico é contribuir concomitantemente com a sustentabilidade dos sistemas ecológicos e com a construção de uma sociedade justa e democrática (CARVALHO, 2001b, 2004, 2008; SAUVÉ, 2005; LOUREIRO, 2009; LAYRARGUES, LIMA, 2011).

$E m$ contestação às abordagens da EA que empregam o conceito de cidadania indistintamente, acarretando em seu esvaziamento, autores vinculados a essa vertente advertem sobre a necessidade de clarificar o seu significado e ampliar o referencial de práticas de formação da cidadania na EA. (CARVALHO, 2004, 2008; LAYRARGUES, 2006; LOUREIRO, 2009; LAYRARGUES, LIMA, 2011). Com vistas a contribuir com esse escopo, o presente artigo explora as implicações teórico-metodológicas da cidadania com 
a EA. Inicialmente nos debruçamos sobre o conceito de cidadania e, em seguida, preconizamos a articulação entre a metodologia de AprendizagemServiço e a ferramenta dos Fóruns Comunitários como uma estratégia para a construção da cidadania na EA.

\section{A CIDADANIA COMO HORIZONTE DA EDUCAÇÃO AMBIENTAL}

Assumir a cidadania como horizonte da EA significa, a priori, reconhecer que a questão socioambiental não é exclusivamente um problema de gestão dos recursos naturais, mas uma problemática fundamentalmente ético-política, ou seja, uma problemática situada na esfera pública que conjuga um conjunto de questões conflitivas que problematizam a vida coletiva, produzindo reflexões, normas e valores que interpelam e responsabilizam cada indivíduo e a sociedade pelos destinos do mundo comum (SILVA, 2015).

Buscando o conceito de política em Hannah Arendt ${ }^{3}$ (2010), mas ampliando a sua acepção ao contexto de emergência da questão ambiental (CARVALHO, 2001a), referimo-nos à problemática socioambiental como uma questão política por reconhecer que o meio ambiente é um bem comum que vem sendo negociado e disputado na esfera pública por diferentes atores, cujas decisões e ações afetam de forma positiva ou negativa a vida dos membros da comunidade humana e o meio ambiente. De modo complementar, falamos de uma questão ética (ou moral), porque, tanto no âmbito das deliberações que ocorrem propriamente na esfera pública, quanto na esfera privada, comparecem sistemas de valores e interesses individuais e coletivos, que regulam as relações interpessoais (VÁZQUEZ, 2012) e que, colocados em ação, incidem sobre a questão ambiental resultando em consequências para a vida de pessoas, para a coletividade e para o meio ambiente.

A cidadania, neste sentido, destaca-se como elemento central no escopo da EA por constituir-se como ação concomitantemente política e ética de compromisso com o bem comum.

\footnotetext{
${ }^{3}$ Para a autora, a política diz respeito à convivência e deliberação de pessoas na esfera pública - entendida como mundo comum - para tratar dos assuntos que concernem ao bem comum.
} 
O conceito de cidadania é objeto de amplo debate e porta uma variedade de significados. Por não ser parte de nosso escopo entrar nos pormenores dos significados atribuídos pelas tradições republicana, liberal e comunitarista (CORTINA, 2005), de modo geral, é possível dissociar o conceito em duas macrodimensões complementares, conforme aparecem na literatura (CORTINA, 2005, MARÍN, 2010, TRILLA, 2010). A primeira delas, mais usual e associada ao conceito de Thomas Marshall (CORTINA, 2005), diz respeito ao reconhecimento legal de um indivíduo pelo estatuto jurídico de um Estado, o qual lhe outorga um conjunto de direitos civis (liberdades individuais), políticos (participação política) e sociais (moradia, educação, trabalho, etc.) e deveres que the são correspondentes. A cidadania, nesse caso, está restrita ao reconhecimento legal e vincula-se à nacionalidade.

Na segunda dimensão, a cidadania é concebida como uma prática social que um indivíduo realiza em determinada comunidade visando à garantia efetiva de direitos e comprometido com a sua melhoria. Marín (2010), afirma que, apesar de depender muitas vezes da primeira dimensão, a prática cidadã transcende os parâmetros de um estatuto jurídico, uma vez que depende do sentimento de pertencimento e responsabilidade do indivíduo com uma comunidade, sentimento este que o impele a atuar nos assuntos públicos exercendo valores cívicos.

A despeito da importância do exercício ativo da cidadania para a sua plena realização, a realidade dos fatos revela a redução da noção de cidadania a sua dimensão legalista e a ação dos indivíduos restrita ao cumprimento passivo das leis que determinam sua conduta social, havendo uma fraca disposição ao compromisso e participação efetivos nos assuntos e demandas de dada comunidade. A constatação dessa lacuna tem justificado a busca pela ampliação do significado estritamente legal da cidadania mediante a adição de adjetivos como "participativa" e "ativa" (MARÍN, 2010; TRILLA, 2010).

Outra importante ampliação da noção legalista de cidadania restrita à nacionalidade vem ocorrendo há alguns anos fruto da globalização, da constituição dos Estados poliétnicos e dos governos supranacionais (como é o caso da União Europeia), e também com a emergência da crise ecológica. Conceitos como cidadania cosmopolita, planetária (CORTINA, 2005) ou mesmo ecológica (LOUREIRO, 2009), por exemplo, expressam um conjunto 
complexo de direitos e responsabilidades sociais que não estão limitados ao ordenamento jurídico-político de um Estado, mas são pensados, produzidos e reproduzidos desde a escala de uma comunidade até a extensão do globo terrestre. Essa premissa não visa ignorar as normas jurídicas que regulamentam as relações sociais no interior de diferentes Estados e culturas, tampouco subestimar a importância do reconhecimento jurídico do indivíduo, mas reconhecer que a prática cidadã, hoje, pode ter um bairro como célula de engajamento e atuação cidadã e, ao mesmo tempo, transcender as limitações geopolíticas.

No interior desse debate em torno do conceito de cidadania, elegemos a perspectiva da filósofa espanhola Adela Cortina (2005), para quem o vínculo de um indivíduo com uma comunidade política e a busca pelo bem comum representam o cerne da noção de cidadania. Nessa perspectiva, o cidadão pensado como tipo ideal - é aquele que, além de saber-se portador de um conjunto de direitos previstos no estatuto jurídico de um Estado, reconhece fazer parte de um mundo que ele compartilha com os demais e que é responsável por ele; solidariza-se com as demandas coletivas e empreende ações que visem à melhoria das condições de vida deste mundo comum, que pode estar circunscrito a um bairro, uma cidade, uma nação ou mesmo ao planeta Terra, mas que, em última análise, significa uma comunidade política que partilha direitos e demanda responsabilidades.

Concordamos igualmente com Trilla (2010), quando afirma que o cidadão, mais que um estatuto jurídico passível de burocratização, deve ser, sobretudo, aquele que reconhece na manutenção e garantia dos direitos pessoais e alheios a sua responsabilidade, que se preocupa e se solidariza com os demais. Logo, consideramos que o cidadão pleno é aquele que adere voluntariamente, por opção e não por coerção, a práticas que visem melhores condições de vida para as pessoas e também, na perspectiva ambientalista, para outros seres vivos.

Neste sentido, uma EA para a cidadania, mais que um trabalho educacional dirigido exclusivamente para a formação de sujeitos que "conheçam e respeitem a natureza", visa à transformação das relações socioambientais opressoras e desiguais, e à construção de uma sociedade mais solidária, democrática, justa e sustentável. Isso reclama empreender um 
trabalho pedagógico que possibilite a formação de sujeitos: dotados de sensibilidade e capacidade de identificar criticamente os problemas constitutivos da relação entre os indivíduos, a sociedade e o meio ambiente; que sintam-se implicados a tais problemas e que comprometam-se com seu enfrentamento por meio de ações cotidianas na esfera privada, mas também mediante a participação no âmbito público com seus pares, influindo eticamente no mundo comum.

\section{APRENDIZAGEM-SERVIÇO E FÓRUNS COMUNITÁRIOS}

Proporcionar a formação de cidadãos sensíveis e comprometidos com as demandas do mundo comum, requer a elaboração de estratégias de ensino especialmente dirigidas a este propósito. Neste sentido, diversos autores têm indicado que a construção da cidadania na EA deve ocorrer por meio de metodologias que promovam o engajamento dos educandos com 0 enfrentamento de problemas e conflitos socioambientais reais, de modo que a educação para a cidadania ocorra na prática (LOUREIRO, 2004; CARVALHO, 2008; ARAÚJO, 2012; SILVA, 2015).

A matriz epistemológica deste pensamento se encontra nas proposições pedagógicas formuladas por autores como John Dewey (1971), Anton Makarenko (1975) e Paulo Freire (2005), que postularam a educação escolar como um continuum da vida cotidiana, de modo que as situações de aprendizagem devem estar vinculadas à realidade dos estudantes e dirigidas a finalidades sociais. Cada um a seu modo, tais autores preconizaram o papel ativo do alunado no desenvolvimento dos estudos escolares e a resolução de problemas da realidade empírica como formas de promover uma aprendizagem mais efetiva e significativa.

Alinhados a essa perspectiva, consideramos que a construção da cidadania na EA deve ocorrer mediante a adoção de uma metodologia participativa de aprendizagem, isto é, uma metodologia que conceba o papel ativo dos educandos no processo de construção do conhecimento e adote os problemas concretos da realidade como matéria-prima de um processo educativo que associa aprendizagem e participação social. No âmbito da 
educação formal, acreditamos que isso pode ser feito mediante a articulação entre a metodologia da Aprendizagem-Serviço e os Fóruns Comunitários.

A Aprendizagem-Serviço (ApS) é uma metodologia que vincula intervenções sobre problemas sociais ou ambientais da comunidade ao aprendizado intencional e sistemático de conceitos, competências e valores, preferivelmente vinculados aos conteúdos curriculares (PUIG, 2009; MARTíN, RUBIO, 2010).

A matéria-prima de um projeto de ApS é um problema social ou ambiental concreto, que deve ser enfrentado pelos educandos por meio do desenvolvimento de um projeto no qual assumem o papel de protagonistas. Do ponto de vista de seus procedimentos metodológicos, um projeto de ApS supõe que os educandos entrem em contato direto com os problemas sociais ou ambientais da comunidade; elejam aqueles que serão objeto de estudo e intervenção; conheçam a estrutura dos problemas mediante estudos e pesquisas; e planejem e executem intervenções sobre estes.

Segundo Trilla (2009), o que diferencia a ApS de outras metodologias ativas é o fato de colocar o alunado para trabalhar com situações reais e de utilidade social, transcendendo os muros escolares para implicar os alunos com as necessidades da comunidade, enquanto outras metodologias ativas geralmente recorrem a simulações ou a situações reais cujas demandas estão restritas ao âmbito acadêmico e aos domínios da instituição escolar. O autor pontua que essa distinção é de todo relevante, pois se a ação é fundamental para o aprendizado de conhecimentos e habilidades, uma ação de utilidade social pode desdobrar no aprendizado de valores e competências cívicas, resultando em benefícios para o indivíduo e para a sociedade.

A ApS, porém, não diz respeito à realização de ações esvaziadas de um trabalho reflexivo e de elaboração crítica acerca da realidade sobre a qual se intervém. Ao contrário, o conhecimento crítico e fundamentado sobre as diversas variáveis que constituem a problemática a ser enfrentada é tido como condição fundamental para a formação do educando e, consequentemente, para a escolha e realização de intervenções capazes de atingir o problema de modo eficaz e enfrentá-lo em alguma medida. Nesse sentido, a práxis (açãoreflexão-ação) representa uma síntese da prática pedagógica promovida pela ApS. 
Uma vez que problemas e conflitos socioambientais acionam valores como justiça social, solidariedade, responsabilidade com o bem comum e com as gerações futuras, a reflexão e ação dos educandos sobre problemas reais, com os quais interagem diretamente, potencializa seu vínculo pessoal com os referidos valores e o reconhecimento de que são agentes de transformação social, constituindo importante procedimento para a construção da cidadania (SILVA, 2015). Ao enfrentar problemas reais, os educandos entram em contato com um ambiente rico em vida, com pessoas de carne e osso; não conhecem o problema apenas no campo abstrato, mas o reconhecem de perto, sentem-no, implicam-se com ele, problemas que em toda a sua complexidade suscitam reflexões e geram sentimentos como a indignação, a justiça e a solidariedade, fundamentais para a construção de valores e da cidadania. Sobre isso, Martín (2009) e Silva (2015) destacam que a responsabilidade e compromisso do educando com a resolução de um problema social ou ambiental, uma vez convertida em ação que impacta de modo positivo a realidade, promove sentimentos de satisfação, produzindo bem-estar e, consequentemente, constituindo importante instrumento para a atribuição de valor a virtudes cívicas.

Acreditamos, pois, que a práxis pedagógica inscrita na metodologia da ApS pode aportar consideráveis contribuições para a construção da cidadania na EA. A implicação ativa e direta dos educandos na problematização, no estudo e na intervenção sobre um ou mais problemas que acometem a comunidade do entorno da escola, poderá proporcionar a construção da cidadania no contexto da problemática socioambiental. Isso porque na ApS a formação da cidadania ocorre pelo próprio exercício prático. O processo de aprendizagem se dá no enfrentamento de situações reais e significativas do ponto de vista social, ético e político, e os educandos assumem o papel de protagonistas no desvelamento da realidade em que se inserem, conjugando reflexão, sentimentos e ação como parte de um mesmo processo de transformação pessoal e social.

Um projeto pedagógico em que os educandos entram em contato direto com os problemas da comunidade do entorno da escola vai ao encontro da realização do ideal das cidades educadoras de tornar os ambientes da cidade um espaço de exercício e promoção da cidadania (GADOTTI; PADILHA; 
CABEDUZO, 2004). Ao extrapolar os muros da escola com objetivos pedagógicos claramente direcionados, o ambiente da comunidade converte-se em um objeto de aprendizagem, um contexto de aprendizagem e, ao mesmo tempo, um agente educativo, o que é de suma relevância para um trabalho de EA que visa problematizar a questão ambiental na esfera pública.

Outro importante aspecto relativo à ApS que julgamos de grande relevância para a EA diz respeito à busca pela realização de parcerias entre a escola, os agentes e as instituições da comunidade na execução dos projetos. Tal articulação representa uma preocupação central de autores como Loureiro (2004) e Carvalho (2008) quando da defesa de metodologias participativas na EA. Contudo, apesar de figurar nos principais documentos orientadores do campo da EA, a articulação entre escola e comunidade na realização de projetos comuns tem se mostrado uma das principais lacunas da EA no âmbito escolar (BRASIL, 2007b; FERREIRA, 2011). Conforme constatado pela pesquisa intitulada $O$ que fazem as escolas que dizem que fazem Educação Ambiental? realizada pelo Ministério da Educação do Brasil (MEC) (BRASIL, 2007b), a despeito de as escolas atribuírem importância às parcerias com a comunidade, esta, quando ocorre, na maioria das vezes restringe-se a "palestras de sensibilização", à realização de eventos comemorativos ou mesmo a mutirões de limpeza da escola. Os autores afirmam que as escolas ainda têm dificuldades em estabelecer metodologias mais participativas e "[...] de aceitar que os atores sociais comunitários são igualmente sujeitos do processo educativo ambiental" (BRASIL, 2007b, p.193), o que resulta em poucas iniciativas em que escola e comunidade atuam conjuntamente no planejamento, na deliberação e na concretização de projetos.

Particularmente na região Sudeste da federação, a pesquisa denota a incipiência da "participação na agenda pública", ou seja, das ações comuns pela melhoria dos espaços públicos interno e externo da escola. O destaque maior é dado ao contexto de escolas públicas situadas nas periferias urbanas, as quais convivem com a questão da pobreza e da violência, sendo, este último aspecto, um dos maiores entraves para a realização de trabalhos na comunidade.

Diante desse quadro, endossamos a importância de que instituições e agentes que atuam na comunidade possam atuar em conjunto com a escola na 
definição e na realização de projetos educacionais em que educandos e outros atores sociais se co-impliquem na resolução dos problemas socioambientais que lhes concernem. Mas para que isso ocorra de modo eficiente, torna-se imprescindível um espaço e um momento para a formalização das parcerias, bem como para a sistematização do diálogo e das deliberações. Uma ferramenta que se constitui como um caminho no atendimento a essa demanda são os Fóruns Comunitários.

Concebido como base de sustentação do Programa Ética e Cidadania desenvolvido pelo Ministério da Educação (MEC) entre os anos de 2003 e 2010 (BRASIL, 2007a), os Fóruns Comunitários tem como principal função reunir os diversos segmentos da escola e da comunidade do entorno na organização e no desenvolvimento de projetos comuns relacionados aos temas da ética e da cidadania, tais como convivência democrática, violência, meio ambiente, direitos humanos e inclusão social. Com composição que pode variar de acordo com a realidade da unidade escolar e da comunidade em que esta se insere, podem dele participar: docentes, corpo diretivo e demais servidores da escola; alunos e seus familiares; e também líderes comunitários, representantes de entidades sociais e comerciantes do entorno da escola (BRASIL, 2007a; ARAÚJO, 2012).

Os Fóruns Comunitários têm como atribuição definir o tema ou as pautas éticas que devem ser incorporados ao currículo escolar e desenvolvidos na escola e no bairro, com o duplo objetivo de promover a educação dos estudantes e contribuir com a melhoria ou solução de problemas da comunidade. Além disso, outros Fóruns devem ser realizados, dentro de um mesmo programa ou módulo temático, com a finalidade de acompanhar o desenvolvimento das atividades. É também no Fórum que se estabelecem compromissos e parcerias acerca do projeto educacional (BRASIL, 2007a; ARAÚJO, 2012).

No contexto da EA, os Fóruns Comunitários constituem uma proposta capaz de contribuir sobremaneira com a construção e o exercício da cidadania. Primeiro porque deve ser um ambiente democrático e participativo onde os conflitos éticos e problemas político-sociais da comunidade são desvelados, analisados e debatidos com a intenção de transformação da realidade. Aplicado à temática ambiental, pode auxiliar na realização de uma das 
principais finalidades da EA propostas pelo Programa Nacional de Educação Ambiental (ProNEA) e pelo Tratado de Educação Ambiental para Sociedades Sustentáveis e Responsabilidade Global (BRASÍLIA, 2005), a saber, configurar espaços democráticos e participativos de gestão ambiental comunitária, enquanto instrumentos de aprendizado e emancipação social. Em segundo lugar, porque se desdobra na participação cidadã coletiva sobre o âmbito público e, com isso, representa uma instância do fazer político no qual os indivíduos deliberam e atuam conjuntamente em torno do bem comum. O Fórum, em sua função educativa, pode demonstrar a importância que a ação conjunta e organizada exerce sobre a transformação da realidade e superação das contradições sociais, o que é fundamental para que os educandos percebam que as ações individuais empreendidas no plano privado, embora essenciais, são insuficientes para o enfrentamento consistente da questão socioambiental.

Assim, no desenvolvimento de projetos de EA que promovem 0 engajamento dos educandos com 0 enfrentamento de problemáticas socioambientais da comunidade, os Fóruns Comunitários constituem valioso recurso para o estabelecimento de parcerias entre escola e comunidade. Conforme demonstrado por Silva (2015), por meio dos Fóruns, atores e instituições da comunidade podem participar ativamente de um projeto de EA junto à escola: na definição dos problemas socioambientais que prioritariamente devem ser tematizados pelos educandos; na realização de atividades de estudo em sala de aula; em pesquisas de campo que visem à compreensão de tais problemas; e também na realização das intervenções dirigidas ao seu enfrentamento.

\section{ARTICULANDO APRENDIZAGEM-SERVIÇO E FÓRUNS COMUNITÁRIOS EM UM PROJETO DE EDUCAÇÃO AMBIENTAL}

Com o intuito de explorar a aplicação prática dos referidos parâmetros teórico-metodológicos, apresentaremos uma breve descrição dos procedimentos de um projeto de EA fundamentado nos princípios da ApS e que adotou os Fóruns Comunitários como ferramenta pedagógica. O projeto foi desenvolvido com cinco turmas do 6 o ano do Ensino Fundamental II, em uma 
escola pública brasileira localizada na periferia da cidade de São Paulo, caracterizada por um contexto de vulnerabilidade socioambiental (SILVA, 2015).

O tema disparador do projeto foi "problemas socioambientais do entorno da escola". A despeito do seu caráter demasiado genérico, a escolha do tema decorreu do reconhecimento da existência de diversos problemas socioambientais da comunidade que poderiam ser tematizados e da opção por possibilitar à comunidade eleger aqueles que Ihes pareciam mais relevantes. Além disso, a opção pelos problemas socioambientais da comunidade como tema do projeto justificou-se pela concepção de que a questão ambiental é uma questão de caráter fundamentalmente ético-político.

No que concerne aos procedimentos metodológicos, o projeto constituiuse pelas seguintes etapas:

1) Formação de uma comissão de estudantes para organizar um Fórum Comunitário.

Sob a orientação de professores, um grupo de jovens encarregou-se de convidar líderes comunitários para o Fórum, divulgar o encontro na comunidade e na escola e participar da organização no dia de sua realização.

2) Realização do I Fórum Comunitário.

A comunidade do entorno da escola, juntamente com estudantes, professores e demais profissionais da unidade escolar, se reuniram para diagnosticar e debater os problemas socioambientais da comunidade. A questão do lixo foi eleita como tema do projeto a ser desenvolvido pelas turmas do 6ํano, por figurar como principal problema apontado pelo Fórum e ser um conteúdo previsto no currículo, o que permitiria conciliar o desenvolvimento do projeto com o cumprimento dos conteúdos curriculares.

3) Problematização da realidade.

Alunos e alunas realizaram um estudo de campo no entorno da escola para identificar os problemas relativos à questão do lixo. Nessa ocasião, realizaram registros escritos e fotográficos sobre os pontos mais problemáticos, como, por exemplo, um córrego que recebe aporte de esgoto doméstico e lixo e em cujas adjacências encontram-se casas em situação de risco. Os discentes também entrevistaram moradores da comunidade, líderes comunitários e catadores de materiais recicláveis. Em seguida, elaboraram um 
relatório sistematizando os dados do estudo e expondo suas reflexões e sentimentos a respeito.

4) Definição, pelos educandos, de questões geradoras para serem estudadas acerca da problemática do lixo na comunidade e em âmbito geral.

Cada grupo de alunos definiu três perguntas de interesse - cujas respostas desconheciam - para orientar seus projetos. Em seguida, as perguntas foram socializadas e a turma elegeu as três que julgou mais relevantes. A título de exemplificação, alguns temas inscritos nas questões geradoras definidas pelo alunado foram: o preconceito e os conflitos trabalhistas envolvendo os catadores de materiais recicláveis da região; a negligência do poder público com a problemática do saneamento na comunidade; e a falta de preocupação dos moradores da comunidade com a situação ambiental.

5) Estudo dos conteúdos associados às questões geradoras por meio das disciplinas de ciências naturais, língua portuguesa e matemática.

Diferentes situações de aprendizagem foram desenvolvidas a fim de auxiliar os educandos a responderem às suas próprias perguntas. Foram realizadas diferentes atividades que, em seu conjunto, tiveram como objetivo proporcionar a significação, não só cognitiva, mas também emocional, das questões associadas às temáticas estudadas.

6) Elaboração de propostas de intervenção para os problemas da comunidade.

Organizados em grupo, os discentes elaboraram propostas de intervenção para os problemas tematizados ao longo do projeto. Para tanto, tinham como referência os conhecimentos construídos acerca da problemática em geral e de sua manifestação naquela realidade e foram orientados a elaborar ações passíveis de serem colocadas em prática por eles.

7) Apresentação e discussão das propostas de intervenção dos educandos no II Fórum Comunitário.

As propostas dos alunos foram apresentadas para os presentes e, em seguida, foi aberta uma discussão a respeito das potencialidades, lacunas e viabilidade de cada proposta e sobre como cada indivíduo ou instituição poderia colaborar. A partir do debate, firmaram-se compromissos, parcerias e encaminhamentos sobre as soluções propostas pelos alunos. 
8) Reunião de um grupo de alunos e de líderes comunitários com 0 chefe de Gabinete da Subprefeitura do bairro Campo Limpo.

Nessa ocasião, os educandos, acompanhados de um professor e de líderes comunitários, reivindicaram o auxílio da subprefeitura para as intervenções que dependiam disso, o que resultou na parceria da subprefeitura no cumprimento das metas dos estudantes.

9) Produção dos materiais para a intervenção sobre os problemas da comunidade.

Cada grupo de alunos se debruçou sobre a sua proposta de intervenção, a saber: I) distribuição de imãs de geladeira e panfletos adesivados para os moradores da comunidade, tratando de temas como a coleta seletiva, o papel dos catadores de materiais recicláveis na cadeia produtiva e o combate à discriminação desse grupo social. Diferentes grupos dedicaram-se a essa proposta, cada qual desenvolvendo material próprio. O conteúdo dos materiais foi elaborado pelos discentes mediante pesquisas e a sistematização dos conteúdos trabalhados na etapa de estudos (etapa 5); II) distribuição de imãs de geladeira abordando, por meio do gênero textual tirinhas de quadrinhos, as consequências ambientais e sanitárias para a comunidade do descarte incorreto de resíduos sólidos. A produção do material também resultou da sistematização dos conteúdos estudados anteriormente nas aulas de Ciências e Língua Portuguesa; III) revitalização da área às margens de córrego poluído mediante a coleta de lixo (por profissionais da prefeitura), o plantio de mudas e de árvores e a fixação de placas coloridas com frases para efeito de alertar a comunidade sobre a importância de conservá-la; IV) realização de uma campanha sobre reciclagem e recolhimento de óleo de cozinha para a produção de sabão, em parceria com cooperativa de reciclagem da comunidade. Esse grupo elaborou um material adesivado com informações e procedimentos de coleta.

10) Intervenção dos alunos e de moradores na comunidade mediante múltiplas ações de cidadania.

Ao longo de três dias, os educandos foram à comunidade e colocaram em prática as propostas de intervenção supracitadas. Os grupos dedicados a campanhas de sensibilização distribuíram os materiais por eles produzidos e dialogaram com os moradores da comunidade a respeito do tema. Outros se 
envolveram com a limpeza das adjacências do córrego, plantio de mudas e fixação das placas.

11) Avaliação das intervenções e divulgação do projeto na Mostra Cultural da escola.

Após o encerramento do projeto os alunos realizaram uma avaliação sobre os aprendizados adquiridos, os desafios enfrentados e estratégias empregadas, e também acerca da relevância do projeto para suas vidas e para a comunidade. Também organizaram painéis de divulgação do projeto na Mostra Cultural, evento que expõe para a comunidade os trabalhos desenvolvidos pela escola.

A análise dos dados revelou que o engajamento dos estudantes em práticas de cidadania demonstrou ter mobilizado um conjunto de conhecimentos, competências e valores (SILVA, 2015), cujos pormenores, entretanto, não são possíveis explorar nesse artigo. Aqui nos interessa destacar que essas práticas, além de promoverem a construção de conhecimentos e o juízo crítico acerca das temáticas circunscritas ao projeto, propiciaram o reconhecimento da ação coletiva organizada como potente instrumento de transformação socioambiental. Ademais, engendraram sentimentos de satisfação que os educandos associaram à sua ação no mundo e aos valores que permearam o projeto, tais como justiça social, democracia, solidariedade e responsabilidade com o bem comum, o que segundo Araújo (2007) e Blasi (2004), é de importância ímpar para a integração de valores à identidade e, consequentemente, para a formação da cidadania pelas crianças e jovens.

\section{CONSIDERAÇÕES FINAIS}

Ao longo deste artigo defendemos que a cidadania participativa, entendida como prática social concernida com o bem comum, representa 0 cerne e horizonte formativo de uma EA comprometida com a transformação concomitante das injustiças sociais e da degradação ecológica. Contribuir com a formação de indivíduos que se sintam ativamente responsáveis pela construção de um mundo mais justo, democrático e sustentável, para as gerações presentes e futuras, constitui, pois, o objetivo primeiro da EA. 
Para tanto, preconizamos o emprego de metodologias participativas e indicamos a ApS e os Fóruns Comunitários como referências para a construção da cidadania na EA. Uma vez conjugados, possibilitam o desenvolvimento de projetos que implicam os educandos com o enfrentamento de problemas socioambientais reais e proporcionam a vivência de práticas de engajamento com o bem comum. São, por isso, estratégias por excelência de construção da cidadania, uma vez que, por meio delas, a cidadania é vivenciada pela ação prática, comprometendo indivíduos e coletivos com os destinos do mundo comum.

\section{REFERÊNCIAS}

ACSELRAD, H.; HERCULANO, S.; PÁDUA, J. (Orgs.). Justiça Ambiental e Cidadania. Rio de Janeiro: Relume Dumará, 2004.

ALVES, H.P. Vulnerabilidade socioambiental na metrópole paulistana. Revista Brasileira de Estudos Populacionais, São Paulo, v. 23, n. 1, p. 43-59, 2006.

ARAÚJO, U. F. A. Construção Social e Psicológica dos Valores. In: Arantes, V. A. (Org.) Educação e valores: pontos e contrapontos. São Paulo: Summus, 2007. p. 17-64.

. Promoting ethical and environmental awareness in vulnerable communities. The Journal of Moral Education, v. 41, n. 3, p. 389-397, sept., 2012. Special Issue: Moral Education and Environmental Concern.

ARENDT, H. A condição humana. 11. ed. Rio de Janeiro: Forense Universitária, 2011.

BLASI, A. Moral functioning: moral understanding and personality. In: Lapsley, D. K., \& Narvaez, D. (Ed.) Moral development, self, and identity. New Jersey: Lawrance Erlbaum Associates, 2004. p. 335-347.

BRASIL. Ministério da Educação. Programa ética e cidadania: construindo valores na escola e na sociedade. Brasília: MEC, SEB: 2007a.

O que fazem as escolas que dizem que fazem educação ambiental? v. 23, n. 6, 262 p., 2007b. Brasília: SECAD, UNESCO (Coleção Educação para Todos, Série Avaliação).

BRASÍLIA. Ministério do Meio Ambiente. Identidades da Educação Ambiental Brasileira. Brasília: Ministério do Meio Ambiente, 2004. 156p.

CARVALHO, I.C.M. A invenção do sujeito ecológico: sentidos e trajetórias em Educação Ambiental. (349 f.) Tese (Doutorado em Educação) - Faculdade 
de Educação, Universidade Federal do Rio Grande do Sul, Porto Alegre, $2001 a$.

Qual educação ambiental? Elementos para um debate sobre educação ambiental popular e extensão rural. Revista agroecologia e desenvolvimento rural sustentável. Porto Alegre, v.2, n.2, p. 43-51, 2001 b.

Educação Ambiental Crítica: nomes e endereçamentos da educação. In: Brasília. Ministério do Meio Ambiente. Identidades da Educação Ambiental Brasileira. Brasília: Ministério do Meio Ambiente, 2004.

Educação Ambiental: a formação do sujeito ecológico. 4. ed. São Paulo: Cortez, 2008.

CORTINA, A. Cidadãos do mundo: por uma teoria da cidadania. São Paulo: Edições Loyola, 2005.

DEWEY, J. Experiência e educação. São Paulo: Editora Nacional, 1971.

FERREIRA, C.E.A. O meio ambiente na prática de escolas públicas da rede estadual de São Paulo: intenções e possibilidades. (Tese de Doutorado em Educação). Faculdade de Educação, Universidade de São Paulo, São Paulo, 2011.

GADOTTI, M.; PADILHA, P. R; CABEDUZO, A (Orgs.). Cidade educadora: princípios e experiências. São Paulo: Cortez, 2004.

LAYRARGUES, P. P.; LIMA, G. F. C. Mapeando as macro-tendências político-pedagógicas da educação ambiental contemporânea no Brasil. In: VI Encontro Pesquisa em Educação Ambiental (pp. 1-15). VI Encontro Pesquisa em Educação Ambiental: a pesquisa em educação ambiental e a pós-graduação. Ribeirão Preto: USP, 2011.

LOUREIRO, C. F. Educar, participar e transformar em educação ambiental. Revista brasileira de educação ambiental. Rede Brasileira de Educação Ambiental. Brasília: Rede Brasileira de Educação Ambiental. p. 13-20, 2004.

Trajetórias e fundamentos da educação ambiental. 3. ed. São Paulo: Cortez, 2009.

MAKARENKO, A. Poema pedagógico. São Paulo: Editora 34, 2005.

MARÍN, M. A. Educación para la Ciudadanía. In: Puig, J. M. (Coord.) Entre todos: Compartir la educación para la ciudadanía. Barcelona: Horsori Editorial, 2010, cap. 1. pp. 15-32 